Article

\title{
Study on Cold Resistance Performance of Composite Subgrade Structure in Seasonal Frozen Regions
}

\author{
Leilei Han ${ }^{1}{ }^{1}$, Haibin Wei ${ }^{1}$, Yong Zhang ${ }^{2}$, Ji Zhang ${ }^{2}$ and Fuyu Wang ${ }^{1, *}$ \\ 1 School of Transportation, Jilin University, Changchun 130022, China; hanll18@mails.jlu.edu.cn (L.H.); \\ weihb@jlu.edu.cn (H.W.) \\ 2 Jilin Province Highway Group Co., LTD, Changchun 130025, China; guoym16@mails.jlu.edu.cn (Y.Z.); \\ haozg16@mails.jlu.edu.cn (J.Z.) \\ * Correspondence: wfy@jlu.edu.cn; Tel.: +86-151-431-73491
}

Received: 27 May 2020; Accepted: 6 July 2020; Published: 7 July 2020

\begin{abstract}
In order to achieve the purpose of subgrade frost damage control and waste utilization, this paper proposes a specific kind of composite subgrade structure which is suitable for subgrade in seasonal frozen regions, especially wet subgrade. The composite subgrade structure is composed of extruded polystyrene (XPS) plates as a cold resistance layer and modified subgrade soil with excellent frost resistance which can consume a lot of oil shale residue and fly ash. To provide valuable reference for engineering applications, an outdoor model test is designed and carried out based on indoor test results and actual engineering data. The cold resistance performance of this new type subgrade structure is evaluated by comparing the temperature distribution, energy transfer, and freezing index of the composite subgrade and the common subgrade during the freezing process. The results show that, firstly, the cold resistance layer can effectively preserve temperature inside the subgrade and form a positive temperature zone beneath XPS plates, which can ensure that the subgrade soil in a certain range will not freeze during the freezing period. Secondly, the position with the best cold resistance effect of the cold resistance layer is directly under the XPS plate. In actual application, the key position should be covered as completely as possible by XPS plates to ensure the cold resistance effect. Thirdly, the cold resistance layer can not only protect subgrade soil under XPS plates from frost damage, but also raise and keep the service temperature of the structure above XPS plates in a certain range, which is beneficial to the cold resistance durability of the entire road. This means that the composite subgrade can greatly reduce the occurrence of subgrade frost damage, thereby even improving the service capability of roads in seasonal frozen regions.
\end{abstract}

Keywords: seasonal frozen regions; frost damage control; cold resistance layer; cold resistance durability; temperature distribution

\section{Introduction}

Seasonal frozen regions account for $53.3 \%$ of the territorial area of China [1]. A large number of engineering practices and subgrade damage investigations [2,3] showed that frost heaving and boiling are the main responses to frost damage of highway subgrade in seasonal frozen regions of China. Repeated freezing and thawing of subgrade soil results in a reduction in the durability of road structure and severely affects the service performance of roads, which not only causes hidden dangers to normal operation, but also wastes a lot of money for road maintenance.

The prevention and control of frost damage is mainly aimed at the key factors leading to frost damage. Currently, prevention and control measures of subgrade frost damage in China include the chemical improvement method, subgrade structure improvement method, replacement method, etc. [4]. 
The chemical improvement method involves adding chemicals to the soil to change its physical and chemical properties. Dai et al. [5] solidified light clay in Changchun with base-seal curing agent and found that the modified soil had more significant anti-freezing effect. Huang et al. [6] found that adding gypsum additive to solidified material could improve the strength of cement-reinforced soil when strengthening soft soil foundation using a cement-soil mixing method. By analyzing the reinforcement mechanism, the results showed that an appropriate amount of gypsum additive can be added to the solidified material in the foundation reinforcement project in order to improve the microstructure characteristics of the modified soil and optimize the foundation reinforcement effect. Current research on the chemical improvement method is aimed at specific soil types in certain areas, while it is apparently limited by construction technology and other conditions.

The subgrade structure improvement method is the improvement of soil for subgrade filling. Hu et al. [7] studied a heavy frost-damaged section filled with fly ash and found that the freezing depth of fly ash subgrade was 30\% to 50\% lower than that of soil subgrade. Li et al. [8] studied two kinds of semi-rigid base course materials, namely, lime-stabilized soil and lime-fly ash-stabilized soil, and they obtained the optimal volume of lime which could prevent frost heave progress. Li et al. [9] analyzed the erosion resistance of soil strengthened with lignin, discussed the problems of subgrade strengthened by lignin, and forecasted the prospect of its application. Russo et al. $[10,11]$ studied the technology of foundation stability when excavating tunnel in water-bearing soft rock and loose sand. The use of these technologies can improve the stability of the subgrade and ensure the safety of the project. The subgrade structure improvement method can improve the cold resistance performance of subgrade to some extent; however, some of the methods have poor stability under the circumstance of repeated freezing and thawing, which leads to a sharp reduction in the improvement effect. Furthermore, it lacks actual projects to verify its long-term stability.

The replacement method refers to replacing all the frost heave-sensitive soil within the freezing depth of subgrade with weak frost heave soil or non-frost heave soil. A test carried out in the Xinjiang Corps reclamation area showed that replacing soil with aeolian sand between $60 \%$ and $70 \%$ of the maximum freezing depth and a pavement structure layer can effectively prevent and control frost heave damage of tertiary highways and below [12]. Some researchers studied the performance of coarse-grained soil under the circumstance of repeated freezing and thawing and found that replacing coarse-grained soil could reduce the occurrence of frost heave. However, under the condition of repeated freezing and thawing, the water content of coarse-grained soil would increase sharply, which means that frost boiling would still happen $[13,14]$. The replacement method is easy to implement and has a wide range of applications, but the anti-freezing effect is directly related to the replacement depth. According to related research [15], the cost is higher when transporting non-frost heave soil over a long distance or when the depth of soil replacement is more than one-third of the frozen depth. Moreover, sand and gravel are usually adopted as replacement materials of wet subgrade in seasonal frozen regions. To ensure that the subgrade is protected from groundwater, the replacement depth is usually deeper, and a larger amount of sand and gravel are needed. The shortage of sand and gravel is continuing, and it is becoming more and more serious. Relevant policies also restrict the mining of river stones, which results in raw material prices and road construction costs skyrocketing. Thus, there is an urgent need to find an alternative to river stone to relieve this pressure [16]. On the basis of meeting basic requirements with regard to the specification for subgrade materials, the subgrade filler in seasonal frozen regions is supposed to have excellent cold resistance durability. According to previous research results from our research group [17], a new type of subgrade filler, which is silty clay modified with oil shale waste residue and fly ash, was put forward. This new type of filler has excellent freezing and thawing resistance stability and can effectively improve the durability of wet subgrade in seasonal frozen regions. Application of the modified soil to highway subgrade can realize the reuse of waste resources, save sand and gravel, and reduce the engineering cost, which is in line with the concept of sustainable development. 
The above methods are all based on improving the freeze and thaw resistance durability of subgrade filler with certain limitations. If the negative temperature energy can be prevented from entering the subgrade, the freezing of subgrade filler in the working area can be reduced. Meanwhile, if the material with excellent frost resistance can be adopted as subgrade filler, the freeze and thaw resistance durability of the subgrade will be greatly improved, especially the wet subgrade in seasonal frozen regions.

In permafrost areas, both the construction of a thermal insulation layer and the increase of subgrade can increase the thermal resistance in order to protect the permafrost. Mao et al. [18] took an actual highway project as an example and pointed out the problems of thermal insulation layer subgrade adopted as an engineering measure to control the stability of permafrost subgrade. Dong et al. [19] put forward a composite subgrade consisted of an L-type heat pipe and gravel insulation board in order to maintain the thermal stability of a wide and high-grade highway in a permafrost area and to protect the underlying permafrost. They studied the thermal stability of composite subgrade using an indoor model test and numerical method.

Based on previous research results, this paper puts forward a composite subgrade construction, which consists of extruded polystyrene (XPS) plates and silty clay modified with oil shale waste residue and fly ash. The cold resistance performance of this structure under the natural conditions of winter in Changchun was analyzed, and its cold resistance effect was evaluated, aiming at providing solutions and references for subgrade in seasonal frozen regions, especially for wet subgrade.

\section{Materials and Methods}

\subsection{XPS Plates}

XPS plates are a kind of foam with a perfect honeycomb structure, which is rigid and closed-cell. Because of its excellent engineering characteristics of low thermal conductivity, good thermal insulation performance, and high compressive strength, XPS plates are suitable for road engineering. The compressive strength of XPS plates adopted in this study was $400 \mathrm{kPa}$. According to the relevant literature [20], the load of traffic and structure weight transferred to the top surface of the subgrade through the pavement structure was $50-100 \mathrm{kPa}$, which is far less than the compressive strength of an XPS plate. The basic parameters of XPS plates used in this paper are shown in Table 1.

Table 1. Parameters of the extruded polystyrene (XPS) plates.

\begin{tabular}{ccccc}
\hline Apparent Density & $\begin{array}{c}\text { Compressive } \\
\text { Strength }\end{array}$ & $\begin{array}{c}\text { Volume Water } \\
\text { Absorption }\end{array}$ & \multicolumn{2}{c}{ Thermal Conductivity $\left(\mathbf{W} / \mathbf{m} \cdot{ }^{\circ} \mathrm{C}\right)$} \\
\hline $0.04 \mathrm{~g} / \mathrm{cm}^{3}$ & $410 \mathrm{kPa}$ & $0.39 \%$ & $0.0245\left(20{ }^{\circ} \mathrm{C}\right)$ & $0.0243\left(-18{ }^{\circ} \mathrm{C}\right)$ \\
\hline
\end{tabular}

It can be easily figured out that the thickness of XPS plates is the main factor affecting the thermal insulation effect of the cold resistance layer [21-24]. In consideration of preventing negative temperature energy from entering, a thicker XPS should result in a better cold resistance effect. However, there is not a linear relationship between the cold resistance effect and the thickness of the XPS plates. As the thickness of the XPS plate increases, the degree of the cold resistance effect decreases gradually. Additionally, it is also economically unreasonable if the XPS plates are too thick. Therefore, the thickness of XPS plates can be obtained according to the thermal resistance equivalence and specific parameters. The calculation process is as described below.

According to some studies [25-28] and engineering data, it can be concluded that the range of road freezing depth in Changchun is 150-250 cm. The typical pavement structure in the northeast area was adopted, which consists of asphalt concrete $(18 \mathrm{~cm})$, cement stabilized macadam $(54 \mathrm{~cm})$, and graded macadam $(20 \mathrm{~cm})$. To effectively maintain the cold resistance effect, the thermal resistance of XPS plates and the pavement structure above should be equivalent to the thermal resistance of $250 \mathrm{~cm}$ of silty clay. Before calculating, the thickness of the pavement structure should be converted to the 
thickness of silty clay according to the thermal resistance equivalence. Then, the thickness of XPS plates can be calculated using Equation (1).

$$
\frac{\mathrm{d}_{\mathrm{x}}}{\mathrm{k}_{\mathrm{x}}}=\frac{\mathrm{d}_{\mathrm{s}}}{\mathrm{k}_{\mathrm{s}}}
$$

where $\mathrm{dx}$ and ds are the thicknesses of XPS plates and the equivalent soil, respectively, while $\mathrm{k}_{\mathrm{x}}$ and $\mathrm{k}_{\mathrm{s}}$ are the thermal conductivities of XPS plates and the equivalent soil, respectively.

The values of the thermal conductivity of the road structure layers are shown in Table 2.

Table 2. Thermal conductivity of the road structure layers.

\begin{tabular}{ccccc}
\hline Structural Layer. & Asphalt Layer & $\begin{array}{c}\text { Cement Stabilized } \\
\text { Layer }\end{array}$ & Graded Macadam & Silty clay \\
\hline $\begin{array}{c}\text { Thermal } \\
\text { conductivity }\end{array}$ & $2.10 \mathrm{~W} \cdot(\mathrm{m} \cdot \mathrm{K})^{-1}[29]$ & $1.60 \mathrm{~W} \cdot(\mathrm{m} \cdot \mathrm{K})^{-1}[30]$ & $\begin{array}{c}0.579 \mathrm{~W} \cdot(\mathrm{m} \cdot \mathrm{K})^{-1} \\
{[31]}\end{array}$ & $1.14 \mathrm{~W} \cdot(\mathrm{m} \cdot \mathrm{K})^{-1}[28]$ \\
\hline
\end{tabular}

(1) Equivalent thickness of silty clay above XPS plates

According to Equation (1), the equivalent thicknesses of silty clay for 18-cm-thick asphalt concrete, 54-cm-thick cement-stabilized macadam, and 20-cm-thick graded macadam are $9.8 \mathrm{~cm}, 38.5 \mathrm{~cm}$, and $39.8 \mathrm{~cm}$, respectively. Thus, the equivalent thickness of silty clay above the XPS plates was $87.7 \mathrm{~cm}$ by adding up the values above.

(2) Thickness of XPS plates

According to the data on freezing depth in Changchun and the calculation result above, the equivalent thickness of silty clay is in the range of $62.3 \mathrm{~cm}$ to $162.3 \mathrm{~cm}$. The thickness of XPS plates was calculated as a range of $1.3 \mathrm{~cm}$ to $3.4 \mathrm{~cm}$. The safety factor was used to modify the theoretically calculated thickness value in order to ensure that the XPS plates could indeed block the negative temperature energy. Taking 1.5 as the safety factor, the final result was in the range of $2.0 \mathrm{~cm}$ to $5.1 \mathrm{~cm}$. Referring to the existing engineering and research results [21-24], $5 \mathrm{~cm}$ was selected as the optimum thickness of XPS plates in consideration of the cold resistance effect and cost.

\subsection{New Type of Subgrade Filler}

\subsubsection{Raw Materials}

Oil shale is widely distributed in northeast China. Oil shale waste residue is the solid waste of oil shale after combustion and power generation. The treatment method at present is usually direct accumulation, which occupies a large amount of farmland and has the potential problem of environmental pollution [32]. The oil shale waste residue used in this paper is shown in Figure 1 and its chemical composition is shown in Table 3.

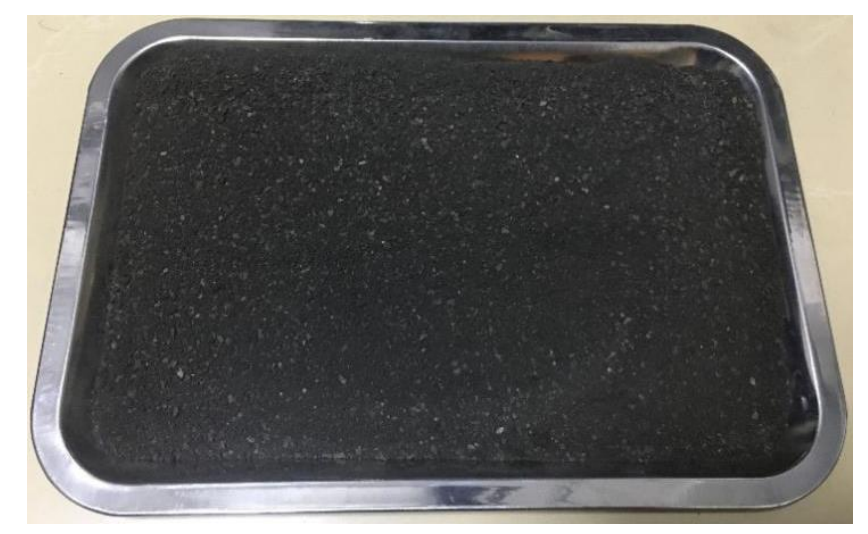

Figure 1. Oil shale residue (2-mm-fine material). 
Table 3. Chemical composition of oil shale residue.

\begin{tabular}{ccccccccccc}
\hline $\mathrm{SiO}_{2 .}$ & $\mathrm{Al}_{2} \mathrm{O}_{3}$ & $\mathrm{TFe}_{2} \mathrm{O}_{3}$ & $\mathrm{CaO}$ & $\mathrm{Na}_{2} \mathrm{O}$ & $\mathrm{K}_{2} \mathrm{O}$ & $\mathrm{MgO}$ & $\mathrm{TiO}_{2}$ & $\mathbf{P}_{2} \mathrm{O}_{5}$ & $\mathrm{MnO}$ & $\begin{array}{c}\text { LOI (Loss on } \\
\text { Ignition) }\end{array}$ \\
\hline 58.27 & 15.64 & 4.93 & 4.62 & 2.67 & 2.48 & 1.58 & 0.72 & 0.31 & 0.10 & 8.50 \\
\hline
\end{tabular}

According to the Chinese Specification GB/T 1596-2017 [33], fly ash used in this paper was grade II and its chemical composition is shown in Table 4. Silty clay used in this paper was excavated from a deep pit of a construction site in Changchun, and its physical properties are shown in Table 5.

Table 4. Chemical composition of fly ash (\%).

\begin{tabular}{ccc}
\hline $\mathrm{SiO}_{2}+\mathrm{Al}_{2} \mathrm{O}_{3}+\mathrm{Fe}_{2} \mathrm{O}_{3}$. & $\mathrm{CaO}$ & $\mathrm{SO}_{3}$ \\
\hline $78.13-88.64$ & $4.12-7.02$ & $0.1-0.72$ \\
\hline
\end{tabular}

Table 5. Physical properties of silty clay.

\begin{tabular}{ccccc}
\hline Liquid Limit. & Plastic Limit & Plasticity Index & $\begin{array}{c}\text { Optimum } \\
\text { Moisture Content }\end{array}$ & $\begin{array}{c}\text { Maximum Dry } \\
\text { Density }\end{array}$ \\
\hline $35 \%$ & $21.1 \%$ & 13.9 & $12.1 \%$ & $1.92 \mathrm{~g} / \mathrm{cm}^{3}$ \\
\hline
\end{tabular}

\subsubsection{Silty Clay Modified with Oil Shale Waste Residue and Fly Ash}

The modified soil was obtained by mixing oil shale waste residue, fly ash, and silty clay in a proportion of 2:1:2, and its basic physical properties are shown in Table 6. The density of modified soil decreased due to the addition of oil shale residue and fly ash. The requirement for the bearing capacity of highway subgrade filling is a CBR(California bearing ratio) value no less than $8 \%$ according to the Specifications for Design of Highway Subgrades (JTG D30-2015). The CBR value of the modified soil met this requirement although the density decreased. According to existing research results [34], the modified soil had excellent freezing and thawing resistance stability.

Table 6. Physical properties of modified soil.

\begin{tabular}{cccccc}
\hline Liquid Limit & Plastic Limit & $\begin{array}{c}\text { Plasticity } \\
\text { Index }\end{array}$ & $\begin{array}{c}\text { Optimum Moisture } \\
\text { Content }\end{array}$ & $\begin{array}{c}\text { Maximum Dry } \\
\text { Density }\end{array}$ & $\begin{array}{c}\text { California } \\
\text { Bearing Ratio }\end{array}$ \\
\hline $32.6 \%$ & $20.2 \%$ & 12.4 & $15.0 \%$ & $1.52 \mathrm{~g} / \mathrm{cm}^{3}$ & $44.9 \%$ \\
\hline
\end{tabular}

\subsection{Filed Test Details}

The test site was located in Jilin University of northeast China, and it was an open and unobstructed space. Its size was excavated as $100 \mathrm{~cm}(\mathrm{~L}) \times 50 \mathrm{~cm}(\mathrm{~W}) \times 110 \mathrm{~cm}(\mathrm{H})$, and a schematic diagram of the outdoor test model is depicted in Figure 2.

Setting the compaction degree as 0.96 , the required quality of modified soil could be calculated according to the volume of the test pit. Oil shale waste residue, silty clay, and fly ash were preprocessed according to Specifications for Design of Highway Subgrades [35] of China before the experiment. The three materials were combined in the optimum mix proportion. Water was added with the optimum moisture content. Then, the mixture was stirred evenly and put in an airtight container for $12 \mathrm{~h}$. The test pit was filled layer by layer, and temperature sensors were buried at corresponding positions. Furthermore, surface galling was carried out between layers to ensure the integrity of the structure. 


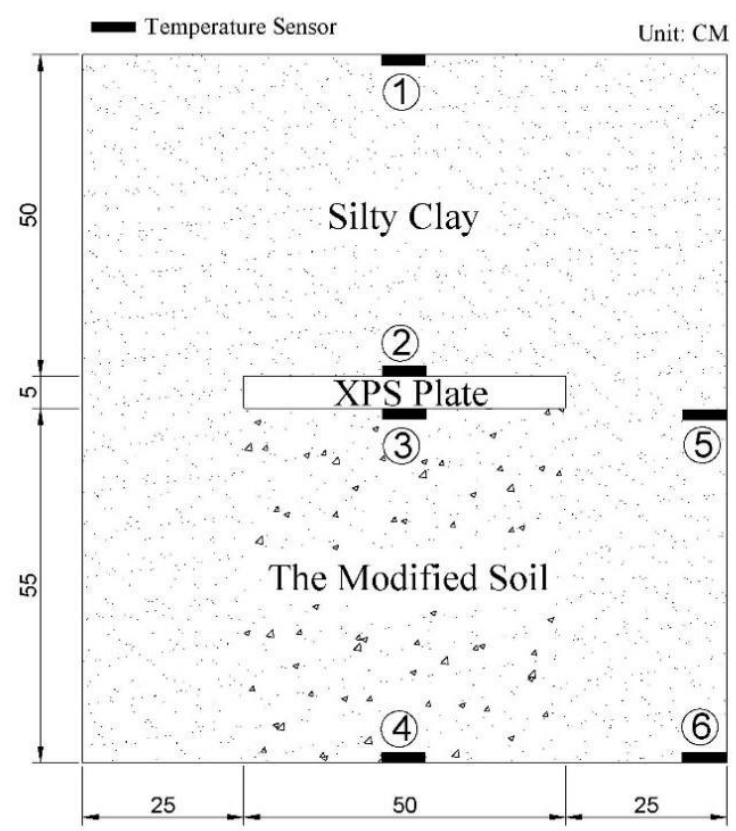

Figure 2. Schematic diagram of the outdoor test model.

To ensure the stability of the XPS layer structure, the XPS plate needed to be laid using a staggered joint, and the side of the plate was bonded with glue. In practical engineering applications, it is necessary to lay a layer of waterproof geotextile on the XPS plate to ensure that the water from the pavement structure does not enter under the plate, thereby improving the integrity of the XPS plate. The temperature sensor used in this test was the XHS-DS18 semiconductor intelligent sensor produced by Changsha Xianghao Electronic Technology Co., Ltd. The measuring range was $-55^{\circ} \mathrm{C}$ to $125^{\circ} \mathrm{C}$ and its measuring accuracy was $0.5^{\circ} \mathrm{C}$. The matching temperature reading instrument for data acquisition was the SZZX-ZH instrument produced by Changsha Sanzhi Electronic Technology Co., Ltd.

From the end of the test model to the start of monitoring data, 30 days were reserved to allow the internal state of the model to become stable and uniform. Aiming at evaluating the cold resistance performance of the structure, the test period included the process from pre-freezing to fully freezing of normal subgrade, for which the monitoring period was 102 days from November 2018 to February 2019.

\section{Results and Discussion}

The temperature of air is the key factor causing variation of the temperature distribution inside the subgrade. The air temperature variation during the monitoring period is depicted in Figure 3 according to the monitoring data.

This paper studied the cold resistance effect of the composite subgrade structure in the freezing process. It can be seen from Figure 3 that the monitoring period included a complete freezing process. 


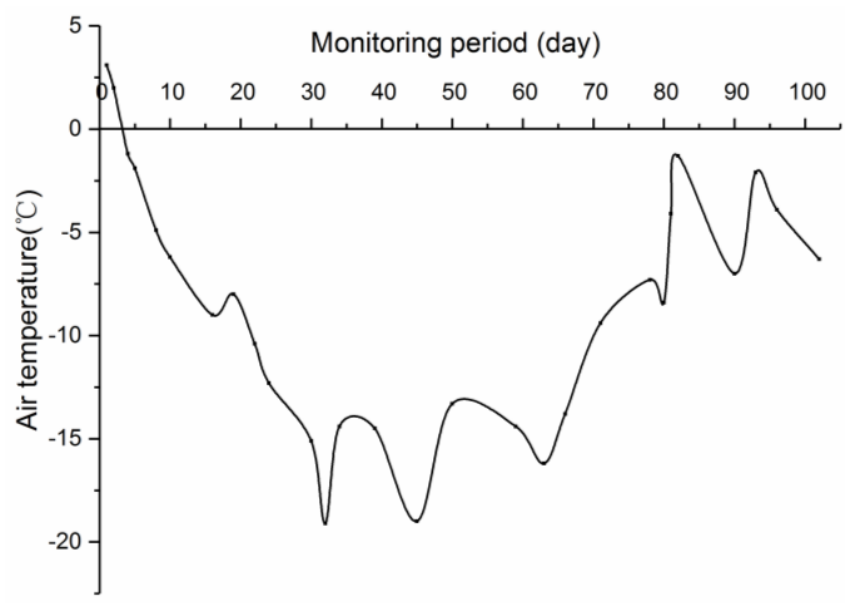

Figure 3. Diagram of air temperature variation during the monitoring period.

\subsection{Temperature Distribution of Subgrade during Monitoring Period}

A temperature distribution map was drawn to evaluate the cold resistance performance of the composite subgrade. Linear interpolation was used to deduce the distribution. Due to the symmetry of the subgrade model, it was equivalent to monitoring the temperature data of 10 control points, with subsequent interpolation along the width and depth. The transverse axis refers to the monitoring process and the longitudinal axis refers to subgrade depth, as demonstrated in Figures 4 and 5.

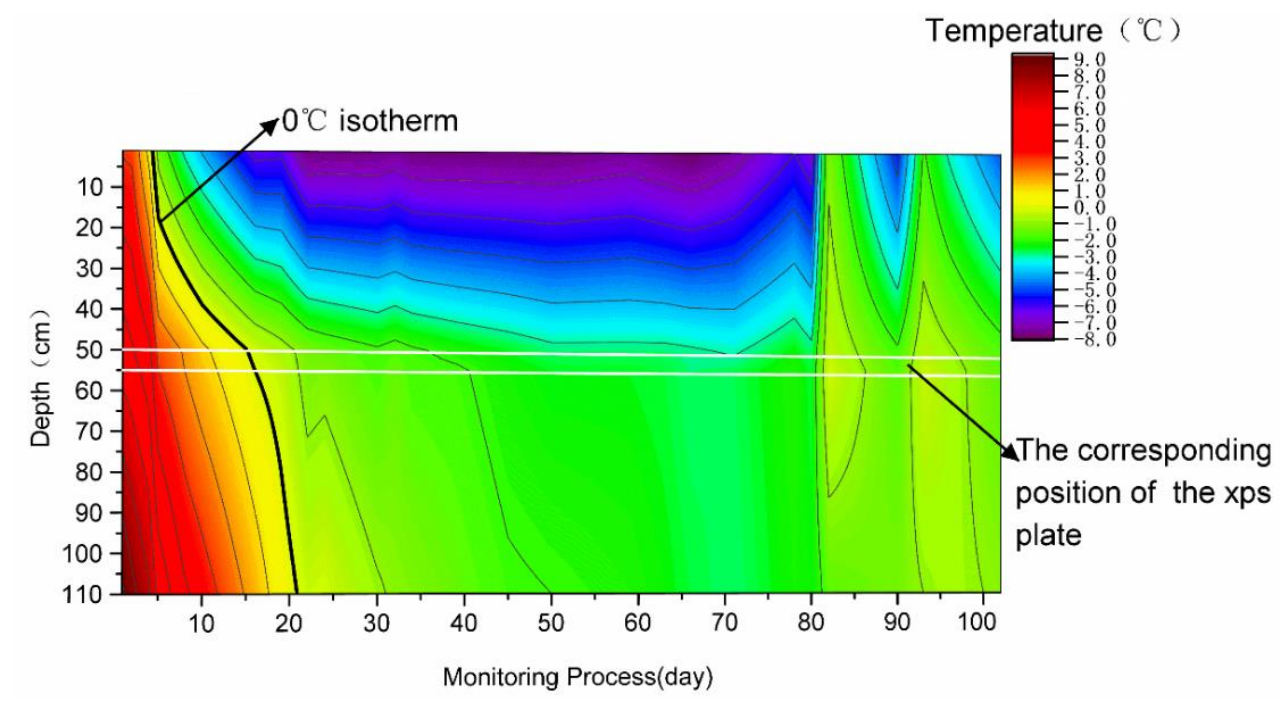

Figure 4. Temperature distribution map of the subgrade without a cold resistance layer. 


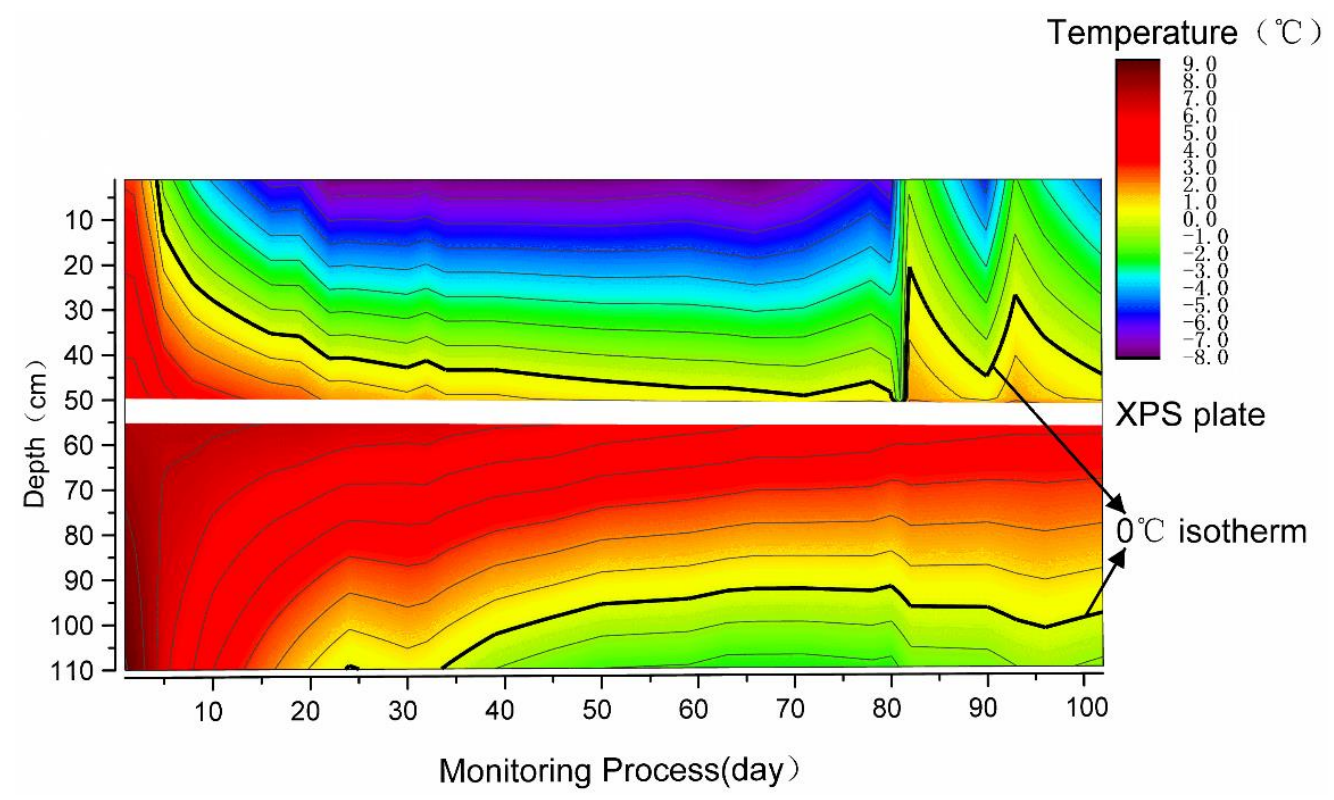

Figure 5. Temperature distribution map of the subgrade with a cold resistance layer.

It can be seen clearly from Figures 4 and 5 that setting the XPS plates had a significant impact on temperature distribution inside the subgrade.

For the subgrade without a cold resistance layer, the $0{ }^{\circ} \mathrm{C}$ isotherm extended rapidly from top to bottom and reached the bottom of the subgrade on the 22nd day with a decrease in ambient temperature. The whole subgrade was in a completely negative temperature condition which was maintained until the monitoring process ended, and the temperature distribution inside the subgrade was fully controlled by ambient temperature.

However, the temperature distribution map of the subgrade with a cold resistance layer was totally different. The temperature distribution above the XPS plates was mainly controlled by ambient temperature, and the $0{ }^{\circ} \mathrm{C}$ isotherm extended more slowly. Compared to the case without a cold resistance layer, the $0^{\circ} \mathrm{C}$ isotherm tended to be basically stable, and it was completely above the XPS plates in the whole monitoring period. The temperature distribution under XPS plates attenuated downward, and its attenuation amplitude was smaller based on the color variation. The temperature distribution of most areas was demonstrated in red and yellow, which means that the temperature was positive. In particular, for the region 15-20 cm near the bottom of the XPS plates, the temperature stayed red in the whole monitoring period. On the 34th day, the phenomenon of negative temperature appeared at the bottom of the subgrade, and the $0{ }^{\circ} \mathrm{C}$ isotherm extended upward slowly until $18 \mathrm{~cm}$ away (the 80th day) from the bottom of the subgrade. Then, the $0{ }^{\circ} \mathrm{C}$ isotherm stopped rising. There are two possible causes for this phenomenon. Firstly, the effective range of the thermal insulation of XPS plates was limited and soil beyond the range would freeze. Secondly, the size of the XPS plates buried in the subgrade model was not big enough and the temperature distribution at the bottom of the model was invaded by negative temperature energy from the ambient soil, as shown in Figure 6 .

It is well illustrated in Figure 6 that negative temperature energy spread downward along the direction of subgrade depth and bypassed the XPS plates, while an obvious phenomenon of thermal accumulation was formed at the bottom of the XPS plates. The subgrade soil beneath the XPS plates was invaded in the most marginal area by the negative temperature energy of the ambient soil. The degree and the range of energy invasion were controlled by the boundary conditions of the subgrade model, which was the air temperature input. As can be seen from Figure 5, up to 18-cm-deep soil was attacked by negative temperature energy, and the temperature dropped below $0{ }^{\circ} \mathrm{C}$. It can be estimated that when the XPS plates were big enough to ensure that the subgrade soil in key parts (such as the subgrade soil beneath the carriageway) was not attacked by negative temperature energy, the cold resistance effect would be very prominent. 


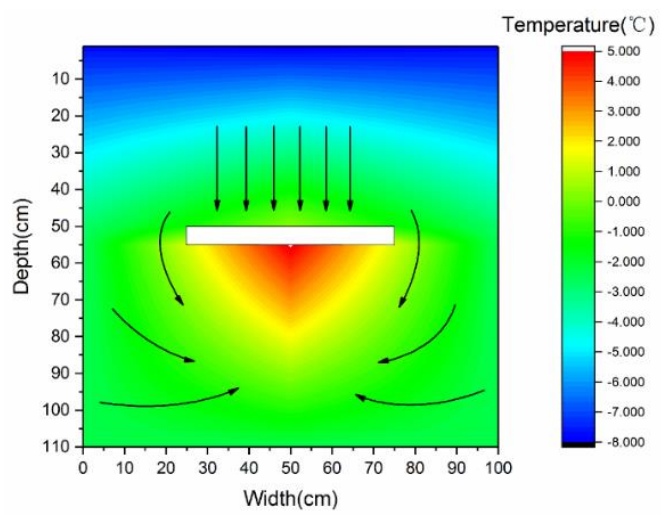

Figure 6. Schematic diagram of negative temperature flow.

\subsection{Temperature Distribution in Different Freezing Stages}

In order to illustrate the cold resistance performance of XPS plates more effectively, a schematic diagram of temperature distribution in different stages was drawn based on outdoor model data. Taking the position of the $0^{\circ} \mathrm{C}$ isotherm inside the common subgrade as a reference, schematic diagrams upon initially freezing (the 10th day), deeply freezing (the 20th day), and fully freezing (the 80th day) were drawn, as shown in Figure 7.

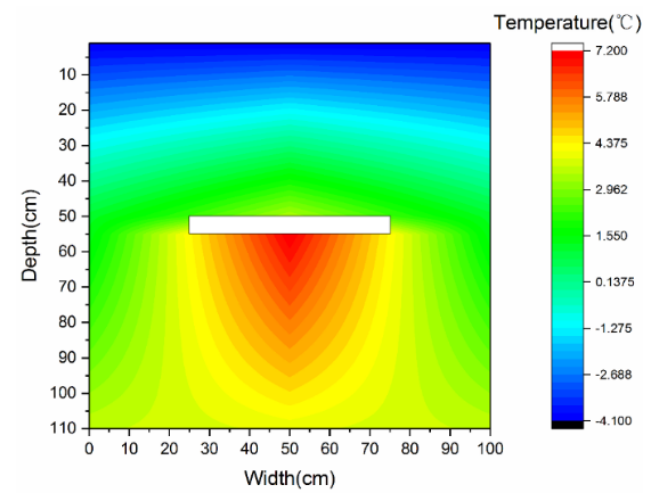

(a)

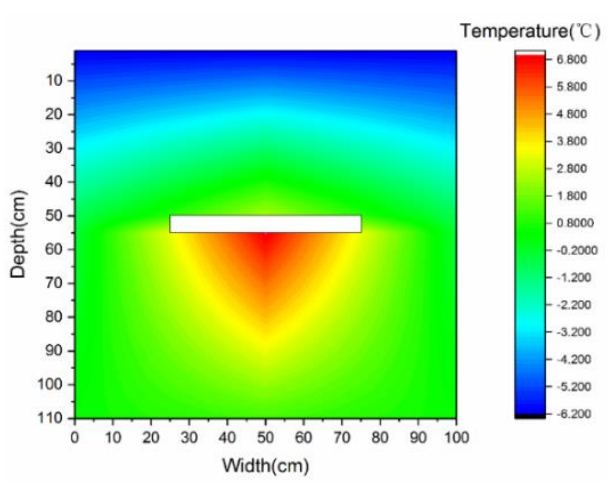

(b)

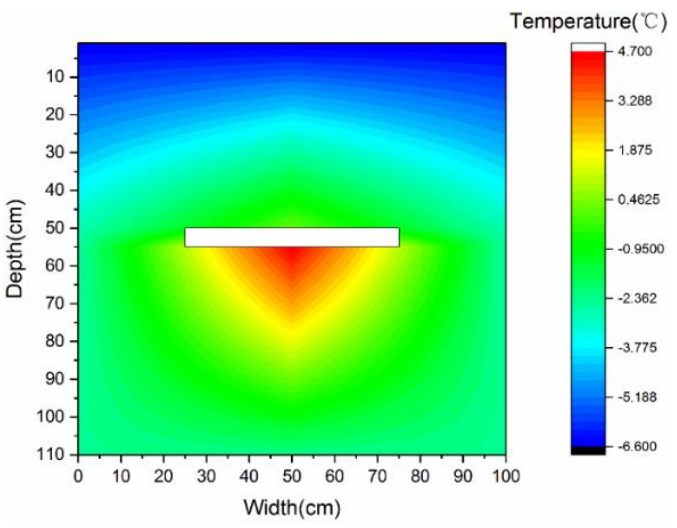

(c)

Figure 7. Schematic diagrams of temperature distribution inside subgrade at different stages: (a) initially freezing; (b) deeply freezing; (c) fully freezing.

As illustrated in Figure 7, the temperature distribution at different stages was different, and the positive temperature range was reduced as the freezing process continued. The change from (a) to (b) in Figure 7 shows that the temperature distribution inside the subgrade changed dramatically due to 
the rapid diffusion downward of negative temperature energy in a short span of 10 days. A comparison between (b) and (c) shows that the temperature distribution inside the subgrade tended to stabilize as the freezing process went on for 60 days, and the effective thermal insulation range of XPS plates was concentrated directly beneath the XPS plates.

\subsection{Temperature Variation Right beneath the XPS Plates}

To illustrate the cold resistance performance of the cold resistance layer with temperature distribution inside the subgrade more precisely, the temperature at the bottom center of the XPS plates was compared with the temperature at the corresponding position of the common subgrade, as depicted in Figure 8.

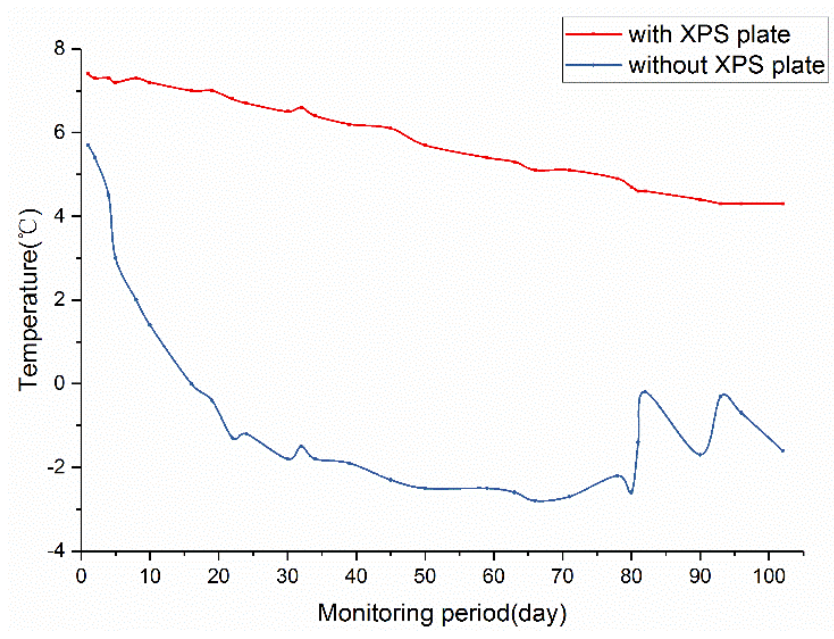

Figure 8. Temperature variation diagram of the subgrade with and without XPS plates.

Figure 8 depicts that the temperature beneath the XPS plates reduced slowly and tended to eventually stabilize at $4{ }^{\circ} \mathrm{C}$, which resulted in the subgrade soil not being frozen. The temperature beneath the XPS plates decreased by only $3.1{ }^{\circ} \mathrm{C}$ during the whole monitoring period. The temperature at the corresponding position of the common subgrade decreased sharply by about $7.7^{\circ} \mathrm{C}$ in the beginning. Then, it tended to stabilize between $-2{ }^{\circ} \mathrm{C}$ and $-3{ }^{\circ} \mathrm{C}$, and the soil began to freeze. After the stable period, the soil temperature fluctuated because of the fluctuation of air temperature. The difference between the temperature at the bottom center of the XPS plates and that at the corresponding position of the common subgrade at the same time is illustrated in Figure 9.

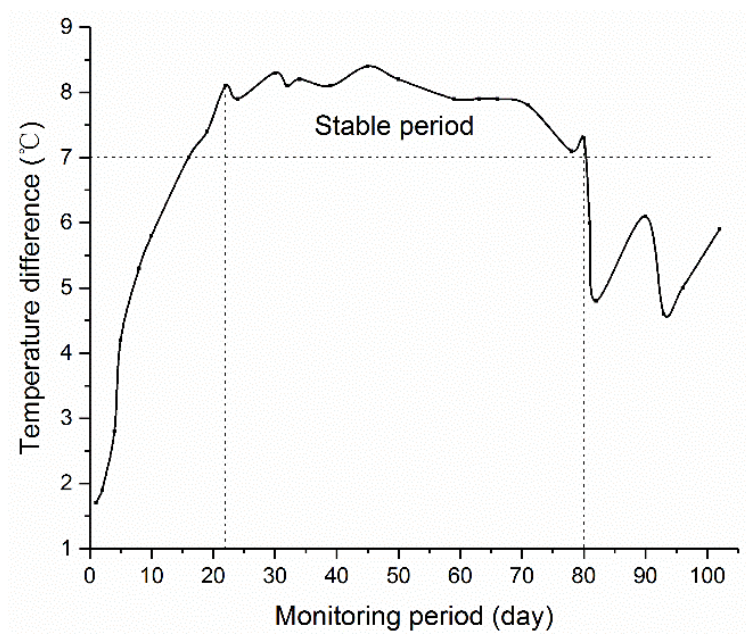

Figure 9. Temperature difference diagram between the bottom center of the XPS plates and the corresponding position of the common subgrade. 
As evident from Figure 9, the temperature difference curve increased rapidly by about $6.4^{\circ} \mathrm{C}$ in the first 20 days and then tended to stabilize between $7.5^{\circ} \mathrm{C}$ and $8.5^{\circ} \mathrm{C}$. After the 80th day, the temperature interpolation fluctuated because the change in air temperature led to variation of the temperature distribution inside the subgrade. In other words, the application of a cold resistance layer can preserve the temperature at $55 \mathrm{~cm}$ under the atmospheric contact surface by about $8{ }^{\circ} \mathrm{C}$.

\subsection{Effective Cold Resistance Depth}

As mentioned above, if the XPS plates are big enough, the cold resistance effect and the influence range of the cold resistance layer can be improved greatly. In the subgrade model, the depth of the positive temperature area at the bottom center of XPS plates denotes the effective cold resistance range of the XPS plates, as demonstrated in Figure 10.

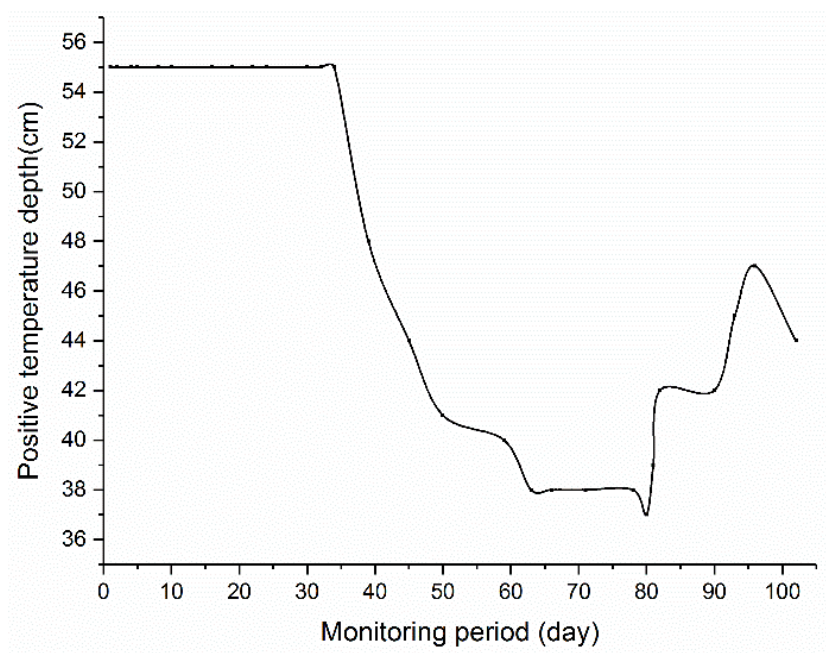

Figure 10. Depth of the positive temperature area at the bottom center of the XPS plates.

The figure depicts that, in the first 34 days, the temperature of the soil beneath the XPS plates was always above $0{ }^{\circ} \mathrm{C}$. Then, because of the invasion of ambient negative temperature energy, the phenomenon of negative temperature appeared and spread upward rapidly until the 80th day. At this time, the positive temperature depth at the bottom of the XPS plates was $37 \mathrm{~cm}$. That is to say, $37-\mathrm{cm}$-thick soil would not freeze, thereby indicating that cthe old resistance layer had excellent cold resistance performance.

\subsection{Analysis of Temperature Rise Effect}

In order to more intuitively incarnate the influence of the cold resistance layer on temperature distribution inside the subgrade, the average values of temperature of the subgrade with and without XPS plates at the same depth were collected during the monitoring period, and the results are listed in Table 7.

Table 7. Average temperature at different depths during the monitoring period $\left({ }^{\circ} \mathrm{C}\right)$.

\begin{tabular}{ccccccccc}
\hline Depth (cm). & $\mathbf{1 0}$ & $\mathbf{2 0}$ & $\mathbf{3 0}$ & $\mathbf{4 0}$ & $\mathbf{6 5}$ & $\mathbf{7 5}$ & $\mathbf{8 5}$ & $\mathbf{9 5}$ \\
\hline With XPS & 2.9 & 1.2 & 0.5 & -0.1 & -0.9 & -0.6 & 0.6 & 0.7 \\
Without XPS & 0.7 & -1.9 & -2.6 & -3.3 & -3.9 & -3.5 & -1.5 & -1.2 \\
$\begin{array}{c}\text { Temperature } \\
\text { difference }\end{array}$ & 2.2 & 3.1 & 3.1 & 3.2 & 3.0 & 2.9 & 2.1 & 1.9 \\
\hline
\end{tabular}

Table 7 shows that the average temperature at the center of the XPS plates increased by about $3.0^{\circ} \mathrm{C}$. The temperature of the subgrade with XPS plates across the full range of depth was higher than 
that of the subgrade without XPS plates. The extent of the increase in temperature took the XPS plates as the center, attenuating upward and downward. For road structures in seasonal frozen regions, this can not only reduce the frost damage of subgrade, but it can also improve the service condition of the bearing layer structure above the XPS plates, which is beneficial to improving road structure durability.

\subsection{Freezing Index}

The freezing index is the sum of the product of duration when the temperature is below $0{ }^{\circ} \mathrm{C}$ in winter or over a year and the daily average temperature or surface soil temperature, which can be used to evaluate the freezing and thawing depth in seasonal frozen regions. In this paper, the freezing index was calculated to evaluate the cold resistance effect of the cold resistance layer as follows:

$$
\mathrm{FI}=\int_{t_{0}}^{t_{1}}|T| d t, T<0^{\circ} \mathrm{C},
$$

where FI is the freezing index, while $t_{0}$ and $t_{1}$ refer to the starting and ending times of the freezing period, respectively. In this test, $t_{0}$ was 17 November and $t_{1}$ was 26 February of next year.

The freezing indexes of point $3 \#$, point $4 \#$, point $5 \#$, and point $6 \#$ were obtained according to Equation (2), and the results are illustrated in Table 8.

Table 8. Freezing indexes of points inside the subgrade during monitoring period.

\begin{tabular}{ccccc}
\hline Point. & 3\# & 4\# & 5\# & 6\# \\
\hline FI & 0 & 114.5 & 153.4 & 134 \\
\hline
\end{tabular}

It can be determined that the freezing index of point $5 \#$ was larger than that of point $3 \#$, which indicates that the XPS plates had an excellent cold resistance effect. Point $4 \#$ was $55 \mathrm{~cm}$ below the XPS plates and its freezing index was 114.5 , which was $14.6 \%$ smaller than that of point $6 \#$. According to the previous analysis, when XPS plates are big enough, the reduction increases sharply. In other words, the freezing index $55 \mathrm{~cm}$ below XPS plates would reduce by more than $14.6 \%$ compared with that of common subgrade in actual engineering when the coverage range of XPS plates is big enough.

\section{Conclusions}

Regarding the lack of the cold resistance durability of subgrade, especially wet subgrade in seasonal frozen regions, a cold resistance layer consisting of XPS plates and silty clay modified with oil shale waste residue and fly ash was proposed to solve the problem of frost heaving and boiling of subgrade in seasonal frozen regions. By carrying out an outdoor model test, the cold resistance performance of the new type of subgrade structure was evaluated and verified. The valuable results from this research are listed below.

(1) The cold resistance layer, which has a great impact on the temperature distribution inside the subgrade, can form a positive temperature zone which is beneficial to the improvement of cold resistance durability of road structures, including the structural layers above XPS plates.

(2) The effective cold resistance area of the cold resistance layer, which is centralized directly beneath XPS plates as the freezing process goes on, tends to stabilize. Thus, key areas should be covered by XPS plates as completely as possible in actual engineering.

(3) The cold resistance layer of composite subgrade can effectively raise the temperature of the subgrade $55 \mathrm{~cm}$ below the atmospheric contact surface by about $8{ }^{\circ} \mathrm{C}$, reduce the freezing index $55 \mathrm{~cm}$ below XPS plates by more than $14.6 \%$, and maintain an effective positive temperature range beneath XPS plates of no less than $37 \mathrm{~cm}$.

(4) After comprehensive analysis, it can be concluded that the cold resistance layer has excellent cold resistance performance which contributes greatly to the improvement of the cold resistance 
durability of subgrade in seasonal frozen regions and reduces the occurrence of road frost damage. Furthermore, it can prolong road service life, which is in line with the concept of sustainable development.

In summary, consisting of XPS plates, which have the advantage of extraordinary cold resistance ability, and modified soil, which features outstanding freeze-thaw durability, the cold resistance layer can certainly solve the frost damage problem of subgrade in seasonal frozen regions. This paper provides a basis for the application of a cold resistance layer structure to treat subgrade diseases in seasonal frozen regions.

Author Contributions: Conceptualization, H.W.; methodology, L.H., H.W., and J.Z.; software, L.H.; validation, L.H., H.W., and F.W.; formal analysis, L.H.; resources, F.W., Y.Z., and J.Z.; data curation, L.H. and Y.Z.; writing — original draft preparation, L.H.; writing — review and editing, L.H., H.W., and F.W.; project administration, H.W.; funding acquisition, H.W. and F.W. All authors read and agreed to the published version of the manuscript.

Funding: This research was funded by the National Key R \& D Program of China, grant number 2018YFB1600200, as well as the Science and Technology Project of Jilin Province Transportation Department, grant number 2017ZDGC6.

Acknowledgments: The authors express their appreciation for the financial support of the National Key R \& D Program of China, grant number 2018YFB1600200, as well as the Science and Technology Project of Jilin Province Transportation Department, grant number 2017ZDGC6. Our thanks go to the editors and reviewers for their efficient work.

Conflicts of Interest: The authors declare no conflict of interest.

\section{References}

1. Xu, X.; Wang, J; Zhang, L. Physics of Frozen Soil, 2nd ed.; Science Press: Beijing, China, 2010; pp. 1-2.

2. Wang, S.; Chen, Z.; Qin, W.; Yu, L. Mechanism analysis on subgrade frost heaving in seasonal frozen region. J. Highw. Transp. Res. Dev. 2013, 7, 28-33. [CrossRef]

3. $\mathrm{Xu}, \mathrm{J}$. Study on Solutions of Subgrade Disease of Expressway and Establishment of PMS System. Doctoral Dissertation, Jilin University, Jilin, China, 2010.

4. Wu, L.; Qi, W.; Niu, F.; Niu, Y. A review of studies on roadbed frozen damage and countermeasures in seasonal frozen ground regions in China. J. Glaciol. Geocryol. 2015, 5, 1283-1293.

5. Dai, W.; Chen, Y.; Chen, X. Test study on road performance of soils stabilized by BS-100 Model stabilizer in seasonally frozen region. Rock Soil Mech. 2008, 29, 2257-2261.

6. Huang, Y.; Zhou, Z.; Bai, J.; Chen, Q. Micro-experiments on a soft ground improved by cement-mixed soils with gypsum additive. Chin. J. Geotech. Eng. 2010, 32, 1179-1183.

7. Hu, S.; Luan, H. Study on Frost Stability of Fly Ash Roadbed of High Grade Highway in Seasonal Heavy Frozen Area. Highway 2002, 47, 53-58. [CrossRef]

8. Li, C.; Liu, H.; Wei, H. Experimental Study on Engineering Characteristics of Semi-Rigid Base Materials in Seasonal Frozen Region. Subgrade Eng. 2010, 2, 46-48. [CrossRef]

9. Li, J.; Jie, D.; Zhang, T.; Cai, G. Application and Development of Lignin of Industrial By-Product in Geotechnical Engineering. Subgrade Eng. 2015, 1, 43-47. [CrossRef]

10. Russo, G.; Corbo, A.; Cavuoto, F.; Autuori, S. Artificial Ground Freezing to Excavate a Tunnel in Sandy Soil. Measurements and Back Analysis. Tunn. Undergr. Space Technol. 2015, 50, 226-238. [CrossRef]

11. Russo, G.; Corbo, A.; Cavuoto, F.; Manassero, V.; Risi, D.; Pigorini, A. Underground Culture: Toledo Station in Naples, Italy. Proc. Inst. Civil Eng. 2017, 170, 161-168. [CrossRef]

12. Li, S. Frost Heave and Prevention of Highway in Bingtuan Reclamation Area of Xinjiang. Highway. 2008, 10, 237-239.

13. Liu, D.; Lai, Y.; Dong, Y.; Li, S. Experimental Study of Anti-Frost-Heave and Frost Boil Effect of Block-Stone-Interlayer Embankment in Permafrost Regions. Rock Soil Mech. 2012, 33, 753-756. [CrossRef]

14. Li, A.; Niu, Y.; Niu, F.; Liu, H. Research Status of Frost Heaving Properties and Controlling Measures of Coarse-Grained Soil. J. Glaciol. Geocryol. 2015, 37, 202-210. [CrossRef]

15. Su, Q. The Principle and Prevention Countermeasure of Subgrade Soil Heaving in Northeast Region. J. Heilongjiang Inst. Tech. 2001, 15, 2-4. [CrossRef] 
16. Bendixen, M.; Best, J.; Hackney, C.; Iversen, L.L. Time is Running Out for Sand. Nature. 2019, 571, $29-31$. [CrossRef] [PubMed]

17. Wei, H.; Zhang, Y.; Cui, J.; Han, L.; Li, Z. Engineering and Environmental Evaluation of Silty Clay Modified by Waste Fly Ash and Oil Shale Ash as a Road Subgrade Material. Constr. Build. Mater. 2019, 196, 204-213. [CrossRef]

18. Mao, X.; Fan, K.; Yuan, K.; Li, J. Application of XPS Plate as Insulation Layer in Subgrade of Highways in Permafrost Region. Subgrade Eng. 2012, 4, 15-19. [CrossRef]

19. Dong, Y.; Lai, Y.; Chen, W. Cooling Effect of Combined L-Shaped Thermosyphon, Crushed-Rock Revetment and Insulation for High-Grade Highways in Permafrost Regions. Chin. J. Geotech. Eng. 2012, 34, 1043-1049.

20. An, L.; Zhang, F.; Geng, Y.; Lin, B. Field Measurement of Dynamic Compressive Stress Response of Pavement-Subgrade Induced by Moving Heavy-Duty Trucks. Shock Vib. 2018, 2018, 1-12. [CrossRef]

21. Zhang, J.; Huo, M.; Chen, J. Technical Problems and Countermeasures of Highway Roadbed Stability in Permafrost Area, 1st ed.; China Communication Press: Beijing, China, 2008.

22. Kong, J. The Anti-Freeze Expansion of the Insulation Board and the Dynamic Response Analysis in Seasonal Frozen Soil Subgrade. Master Dissertation, Central South University, Changsha, China, 2012.

23. Shang, J. Discussion on Burying Position of Thermal Insulation Material in Subgrade Engineering in Permafrost Area. Subgrade Eng. 2004, 5, 27-28. [CrossRef]

24. Xin, Q. Research on XPS Insulation Board Treatment Technology in Insular Permafrost Subgrade. Master Dissertation, Chang'an University, Xi'an, China, 2012.

25. Zhou, Y.; Li, J. Study on Distribution Model of Standard Frozen Depth in Northeast Permafrost Region. East China Highway. 2010, 2, 86-88.

26. Tan, Y.; Xu, H.; Zhou, C.; Zhang, K.; Cheng, F. Temperature Distribution Characteristic of Subgrade in Seasonally Frozen Regions. J. Harbin Inst. Tech. 2011, 43, 98-102.

27. Zhang, Y.; Du, Y.; Sun, B. Temperature Distribution in Roadbed of High-speed Railway in Seasonally Frozen Regions. Chin. J. Geotech. Eng. 2014, 33, 1286-1296.

28. Zhang, Y.; Wei, H.; Jia, J.; Chen, Z. Numerical Evaluation on Application of Roadbed with Composite Cold Resistance Layer in Seasonal Frozen Regions. J. Jilin Univ. (Eng. Technol. Ed.). 2018, 48, 121-128. [CrossRef]

29. Yan, X.; Ai, T.; You, Q.; Zhang, Y.; Wang, L. Experimental Characteristics of Heat Conduction of Semi-Rigid Base Asphalt Pavement. J. Chang'an Univ. (Nat. Sci. Ed.). 2016, 36, 1-7.

30. Zhang, Y. Experimental Characteristic of Heat Conduction of Aggregates Treated by Cement. Master Dissertation, Chang'an University, Xi'an, China, 2015.

31. Liao, Q.; Tian, N. A Test on the Thermal Conductivity Performance of High-Speed Railway's Graded Broken Stone. Subgrade Eng. 2014, 4, 125-128. [CrossRef]

32. Tan, G.; Zhu, Z.; Gong, Y.; Shi, C.; Liu, Z. Performance Evaluation of Cement-Stabilized Oil Shale Semi Coke as Base or Subbase Course Construction Material. Adv. Mater. Sci. Eng. 2018, 2018, 1-12. [CrossRef]

33. Inspection and Quarantine of the People's Republic of China \& Standardization Administration of China. Fly Ash Used for Cement and Concrete (GB/T 1596-2017); Renmin Communication Press: Beijing, China, 2017.

34. Wei, H.; Zhang, Y.; Wang, F.; Che, G.; Li, Q. Experimental Research on Resilient Modulus of Silty Clay Modified by Oil Shale Ash and Fly Ash After Freeze-Thaw Cycles. Appl. Sci. (Switzerland). 2018, 8, 1298. [CrossRef]

35. Ministry of Transport of People's Republic of China. Specifications for Design of Highway Subgrades (JTG D30-2015); Renmin Communication Press: Beijing, China, 2015.

(C) 2020 by the authors. Licensee MDPI, Basel, Switzerland. This article is an open access article distributed under the terms and conditions of the Creative Commons Attribution (CC BY) license (http://creativecommons.org/licenses/by/4.0/). 